\title{
Androgenesis induction in microspore culture of sweet pepper (Capsicum annuum L.)
}

\author{
Csaba Lantos • Anikó Gémes Juhász • \\ Pál Vági · Róbert Mihály · Zoltán Kristóf • \\ János Pauk
}

Received: 16 May 2011/Accepted: 6 October 2011/Published online: 27 October 2011

(C) Korean Society for Plant Biotechnology and Springer 2011

\begin{abstract}
Isolated microspore culture experiments were carried out in sweet pepper (Capsicum aпnиит L.) $\mathrm{F}_{1}$ hybrid genotypes. In the first experiment, four culture media (W14, B5, MS and NLN) were compared to test their effectiveness in inducing the formation of microsporederived structures in two genotypes. The experiments revealed the superiority of B5 medium. In the second experiment, the effects of different ratios of 2,4-dichlorophenoxyacetic acid (2,4-D) $\left(0,0.1,0.2\right.$ and $\left.0.5 \mathrm{mg}^{-1}\right)$ and kinetin $\left(0,0.2\right.$ and $\left.0.5 \mathrm{mg} \mathrm{l}^{-1}\right)$ were also investigated in B5 medium with two genotypes. The effect of growth regulators were investigated on the production of microsporederived calli and embryo-like structures (ELSs), the ratio of the two and plant regeneration (number of regenerated plantlets) in microspore culture. The histological experiments revealed the differences between the microsporederived ELSs and calli. The most promising results were obtained on the investigated parameters in the presence of $0.1 \mathrm{mg} \mathrm{l}^{-1} 2,4-\mathrm{D}$ and $0.2 \mathrm{mg}^{-1}$ kinetin producing the highest number of plantlets in both genotypes tested. In the response of 11 genotypes, the androgenesis induction was successful in each sweet pepper genotypes tested using the best basic medium and growth regulators combination. In case of 11 genotypes, the number of ELSs ranged from
\end{abstract}

C. Lantos · R. Mihály · J. Pauk ( $₫)$

Department of Biotechnology, Cereal Research Non-Profit

Company, Szeged, P.O. Box 391, 6701, Hungary

e-mail: janos.pauk@gk-szeged.hu

A. Gémes Juhász

Medimat Ltd, XIV utca 37, Budapest 1224, Hungary

P. Vági · Z. Kristóf

Department of Botany, Eötvös Loránd University,

Budapest, P.O. Box 120, 1518, Hungary
20 to 100/Petri dish (an average of 48.1 ELS/Petri dish), while the number of green plantlets varied from 0 to 8 plantlets/Petri dish (an average of 1.5 plantlets/Petri dish) depending on the genotype. The spontaneous rediploidization rate obtained was $25 \%$ in isolated microspore.

Keywords Capsicum annuиm L. · Embryogenesis · Haploid · Histology · Microspore · Sweet pepper
Abbreviations
2,4-D 2,4-Dichlorophenoxyacetic acid
DH Doubled haploid
ELS Embryo-like structure
LSD Least significant difference

\section{Introduction}

Not all species in the Capsicum genus have been described so far, since botanists have not yet been able to fully explore the genus with such a bewildering diversity of species. There are thought to be 25-30 species of Capsicum, of which the following 5 are the most widespread in subtropical and temperate countries: C. anпиит L., C. frutescens Mill., C.baccatum L., C. chinense and C. pubescens (Csilléry 2006). Pepper is one of the most basic ingredients in a number of cuisines around the world. The nutritive value of pepper is high and it is also an excellent source of vitamins C, A, B-complex and E and rich in minerals like molybdenum, manganese, folate, potassium and thiamine (Simonne et al. 1997). Pepper is a widely known crop plant which can be used as a vegetable, an ingredient of sauces, a colouring and pungent agent of foods, or in pharmaceutical applications. 
One of the most fundamental aims of the breeding programmes in Capsicum annuum L. is to establish new marketable cultivars. Biotechnological methods such as the doubled haploid (DH) plant production have the potentials to support the breeding process of these new cultivars (Thomas et al. 2003). Efficient methods to establish uniform DH lines are essential for researchers to map the genetic background of agronomically important traits as well as for breeders to shorten the time of the breeding process required to produce new hybrids and homogenous varieties. Although there are different techniques available in different species to achieve this goal including wide crossing, anther culture, shed- and isolated microspore cultures, the possibilities are rather limited in pepper.

The first results of pepper anther culture were published simultaneously by three different laboratories (George and Narayanaswamy 1973; Kuo et al. 1973; Wang et al. 1973). In the following period, the method was gradually improved (Sibi et al. 1979; Dumas de Vaulx et al. 1981). As a result of further minor improvements (Kristiansen and Andersen 1993; Mitykó et al. 1995; Dolcet-Sanjuan et al. 1997; Kim et al. 2004; Gémes Juhász et al. 2010), the method has already been sporadically applied in different breeding programs (Thomas et al. 2003; Gémes Juhász et al. 2006; Mitykó and Gémes Juhász 2006). Although anther culture is a prospective method for the production of DH plants, an efficient protocol for a genotype-independent system is yet to be developed (Irikova et al. 2011). The most critical factors for the production of embryo-like structures (ELSs) and subsequent plant regeneration include the genotype and growth conditions of donor plants, collection of donor buds in the optimal stage, and stress treatments, as well as the composition of medium and culture conditions (Irikova et al. 2011).

As a result, the limitations of currently available anther cultures, such as their labour intensity, low efficiency, uncontrolled tapetum secretion, possibility of somatic regenerants and their genotype dependency, prompted further efforts to improve anther culture and other alternative methods for DH plant production (Seguí-Simarro et al. 2011). Nowadays, a lot of research effort is focused on improving different DH plant production methods in pepper such as in vivo polyembryony (Jedrzejczyk and Nowaczyk 2009), shed microspore culture (Supena et al. 2006a) and isolated microspore culture (Kim et al. 2008).

It has been known that the composition of media greatly influences the efficiency of microspore culture in any species. However, the amount of published results is limited with regard to isolated microspore culture of Capsicum annиum L. The two liquid media used in the first successful microspore culture experiments were the NLNS (Kim et al. 2008), which is the modified version of NLN (Lichter 1982), and the W14mi (Lantos et al. 2009), the modified
W14 (Ouyang et al. 1989). In these pioneer experiments, androgenesis was induced in growth regulator-free medium as well as in media supplemented with $0.5 \mathrm{mg} \mathrm{l}^{-1} 2,4$ dichlorophenoxyacetic acid (2,4-D) and $0.5 \mathrm{mg} \mathrm{l}^{-1}$ kinetin. A clear understanding of the effects of growth regulators in microspore culture of Capsicum annuum $\mathrm{L}$. requires further studies. The first successful experiments focused on the improvement of microspore culture in hot pepper and spice pepper genotypes. Supena et al. (2006a) published the first microspore culture-derived haploids in Indonesian hot pepper. Isolated microspore culture was established and developed for a hot pepper genotype, 'Milyang-jare' (Kim et al. 2008). Isolated microspore cultures of Hungarian and Spanish spice pepper genotypes were improved by using the wheat ovary co-culture method (Lantos et al. 2009). Experiments conducted with sweet pepper (Capsicum annuиm L.) aimed at improving the efficiency of microspore cultures (Gémesné Juhász et al. 2009; Parra-Vega et al. 2010; Seguí-Simarro et al. 2011). In Capsicum annuum L., the plant regeneration rate was lower than in microspore culture of other Solanaceae species such as tobacco (Touraev et al. 1996). The first promising results prompted further investigations into microspore cultures and into the histology of microspore-derived structures.

In this study, microspore culture experiments were carried out in sweet pepper genotypes. Four different media were compared to test the effects of their macro- and microelements and vitamins on the production of ELSs. The effect of 12 different combinations of growth regulators (2,4-D and kinetin) in induction medium were investigated on the production of microspore-derived structures and plant regeneration. Histological features of microspore-derived ELSs and calli were also monitored and the response of sweet pepper genotypes was tested in isolated microspore cultures.

\section{Materials and methods}

Plant material and donor plant growth conditions

All together, 12 sweet pepper $F_{1}$ hybrid genotypes, namely the Hungarian cecei type (253, 254 and 257), Turkish sivri type (266, 267, 269 and 278), Kapya type (281), Charliston type (287) and Dolma type (291, 292 and 303), were used to carry out the microspore culture experiments. Three generations of donor plants per year were applied in the investigations. The germination and nurturing of the donor plants was conducted in a half-automatic greenhouse (Henssler, Beilstein, Germany) under a 16-h photoperiod with a temperature of $25-32^{\circ} \mathrm{C}$ in daylight and $15-19^{\circ} \mathrm{C}$ in the dark. The seeds were sown in PVC bags containing 1:1 peat and sandy soil mix. After a month, the seedlings were 
planted individually in plastic pots containing the same soil mix. Plants were fertilized once every 2 weeks with Ferticare $^{\mathrm{TM}}$ 15:30:15 S until the appearance of the first buds, and Ferticare ${ }^{\mathrm{TM}}$ 24:8:16 during the period of bud collection (Yara Hungary, Veszprém, Hungary).

\section{Collection of donor buds and pretreatment of anthers}

Flower buds were collected at late uninucleate and early binucleate stages of microspore development as we published earlier for spice pepper (Lantos et al. 2009). The developmental stage of microspores was identified by an Olympus CK2 inverted microscope (Olympus, UK) at $\times 200$ magnification.

$\mathrm{NaOCl}$ solution (2\%) plus 1 drop of Tween-20 were applied to sterilise the collected buds for $20 \mathrm{~min}$, then the donor materials were rinsed three times with sterile distilled water (Millipore Elix 5). Anthers were isolated directly into glass Petri dishes of $55 \mathrm{~mm}$ diameter containing $5 \mathrm{ml} \quad 0.3 \mathrm{M}$ mannitol solution and $200 \mathrm{mg} \mathrm{l}^{-1}$ Cefotaxime (anthers of one bud/Petri dish). The isolated anthers received a heat pretreatment for 7 days in $0.3 \mathrm{M}$ mannitol solution at $32^{\circ} \mathrm{C}$ in the dark.

\section{Microspore isolation and culture conditions}

At the first step of microspore isolation, the pretreated anthers were crushed by a glass rod on the surface of a nylon mesh with $200-\mu \mathrm{m}$ pore size and rinsed through the mesh by $0.3 \mathrm{M}$ mannitol. The microspores were isolated from the suspension by means of mannitol/maltose gradient centrifugation (Harms and Potrikus 1978) which was subsequently modified by the authors (Lantos et al. 2009). Approximately $5 \times 10^{4}$ microspores could be isolated from the pretreated anthers of each single flower bud.

The density of the microspores in the liquid medium was determined by a Burker chamber and the microspore suspension was diluted to $3 \times 10^{4}$ microspores $\mathrm{ml}^{-1}$. The number of pretreated anthers of one donor bud was enough to prepare one Petri dish (35 $\mathrm{mm}$ diameter) containing $1.5 \mathrm{ml}$ liquid medium. Isolated microspores were cultured in 35-mm plastic Petri dishes (Cat. 83.1800; Sarstedt, USA). The pepper microspores were co-cultured with wheat ovaries (genotype CY-45). Ovary donor wheat plants were grown in a greenhouse (16-h photoperiod with a temperature of $18-20^{\circ} \mathrm{C}$ in daylight and $12-15^{\circ} \mathrm{C}$ in the dark). Donor spikes were collected 2 days before pollination. Seven wheat ovaries were added to each Petri dish (35 mm diameter) to support the development of ELS (Lantos et al. 2009). The cultures were incubated at $28^{\circ} \mathrm{C}$ with $80 \%$ air humidity and maintained in the dark for 2 months.
Testing of the effects of culture media and growth regulators

In the first part of our experiments, four different mediamarked B5 (Gamborg et al. 1968), MS (Murashige and Skoog 1962), W14 (Ouyang et al. 1989) and NLN (Lichter 1982)-were used in isolated microspore cultures to test their ability to induce ELSs in two hybrids (genotype 254 and 257). The media were all supplemented with $9 \%$ maltose, $1 \mathrm{~g}^{-1}$ glutamine, $0.5 \mathrm{mg} \mathrm{l}^{-1}$ kinetin, and $0.5 \mathrm{mg} \mathrm{l}^{-1}$ 2,4-D. Also, $200 \mathrm{mg} \mathrm{l}^{-1}$ Cefotaxime was used to prevent contamination. In order to find the optimum ratio of 2,4-D and kinetin 12 combinations of the 2 growth regulators in a $4 \times 3$ arrangement (2,4-D: $0,0.1,0.2$ and $0.5 \mathrm{mg} \mathrm{l}^{-1}$; and kinetin: $0,0.2$ and $0.5 \mathrm{mg} \mathrm{l}^{-1}$ ) were tested on B5 medium, because this medium produced the best result in the previous (effect of basic medium) experiment.

\section{Histological examination}

The chosen developmental stages were fixed in a $4 \%$ formaldehyde solution buffered to $\mathrm{pH} 7.2$ and infiltrated under a slight vacuum. Fixed samples were washed in PBS buffer for 10 minutes, postfixed for lipids in $1 \%$ osmiumtetroxid solution for prospective electron microscopy studies and then dehydrated in graded ethanol series. After dehydration, the samples were embedded in Durcupan (Fluka) resin and $4-\mu$ m-thick sections were cut with a Microm HM 360 microtome. The sections were heat-dried on slides and stained in an aequous solution of $0.5 \%$ toluidine-blue and $0.1 \% \mathrm{Na}_{2} \mathrm{CO}_{3}$ for $5 \mathrm{~min}$. The stained sections were photographed with Olympus $\mathrm{BH} 2$ microscope.

Plantlet regeneration, ploidy level determination and acclimatization of plants

Following the culture period, the microspore-derived ELSs and calli of at least $2 \mathrm{~mm}$ in size were placed onto regeneration medium R1 (Dumas de Vaulx et al. 1981). Regeneration was conducted at $24^{\circ} \mathrm{C}$ under a 16 -h photoperiod at $100 \mu \mathrm{mol} \mathrm{m} \mathrm{m}^{-2} \mathrm{~s}^{-1}$ light intensity. Regenerated plantlets with 1-2 leaves and with well-developed roots were transferred to glass tubes containing growth regulatorfree half-strength MS (Murashige and Skoog 1962) medium with $2 \%$ sucrose, gelatinized with Gelrite $\left(2.8 \mathrm{~g} \mathrm{l}^{-1}\right)$.

The ploidy level of the well-rooted plantlets with 3-4 leaves was determined by flow cytometry using a Partec I flow cytometer (Partec, Münster, Germany). The leaf samples were obtained from the in vitro plantlets in the glass tube. The nuclei were isolated from the plantlets using the protocol published by Doležel et al. (1989). The DNA content of each plantlet was measured three times. 
Table 1 Effects of media on the microspore-derived structures of two sweet pepper genotypes (257 and 254)

\begin{tabular}{llllr}
\hline Genotype & \multicolumn{2}{l}{ Microspore-derived structures (number/Petri dish) } & \multicolumn{2}{c}{ LSD } \\
\cline { 2 - 5 } & B5 & W14 & NLN & MS \\
\hline 257 & $174.00 \mathrm{a}$ & $150.40 \mathrm{a}$ & $64.20 \mathrm{~b}$ & $30.25 \mathrm{~b}$ \\
254 & $84.25 \mathrm{a}$ & $52.25 \mathrm{ab}$ & $42.75 \mathrm{~b}$ & $7.00 \mathrm{~b}$ \\
\hline
\end{tabular}

After carrying out the ANOVA of the collected data, the least significant differences (LSDs) were 40.44 and 36.92 in the experiments of two genotypes. The same letters within a row indicate the data which are not significantly different (at $P=0.05$ )

Diploid control samples were prepared from the leaves of seed-derived pepper plants (Gémes Juhász et al. 2006).

The rooted plantlets with $4-5$ leaves were transferred to plastic pots containing 1:1 mixture of commercial peat and sandy soil mix. During the following 2 weeks, the plantlets were acclimatised in a plastic growth chamber at a relative humidity of $80 \%$. The acclimatised plants were grown in individual boxes (wooden frame boxes covered with cheese cloth) to get self-pollinated DH lines. The spontaneous rediploidisation rate was determined by flow cytometry and the ratios of fertile and acclimatised plants were obtained.

Data collection and statistical evaluation

The investigations were performed in at least four replicates, and mixed microspore populations of the donor buds were used to carry out each experiment which were repeated two times. The number of microspore-derived ELSs and calli were visually counted. During the regeneration period, the number of regenerated plantlets and acclimatised plants were recorded. The collected data were evaluated by ANOVA using the Microsoft ${ }^{\circledR}$ Excel 2002 statistical software developed by the Microsoft, USA.

\section{Results}

Effects of media on the ELS production in isolated microspore culture of sweet pepper (Capsicum anпиит L.)

In the first experiment, the effects of four different media were tested in isolated microspore culture of two sweet pepper genotypes. The total $\mathrm{N}$ content, $\mathrm{N}_{\text {org }}: \mathrm{N}_{\text {inorg }}$ ratio and $\mathrm{NO}^{-}{ }^{-} \mathrm{NH}_{4}^{+}$ratio in the induction media were calculated. These values were the followings in the different media tested: B5 medium: total $\mathrm{N}=39.5 \mathrm{mmol}, \mathrm{NO}^{-}: \mathrm{NH}^{+}=$ 96:04, $\mathrm{N}_{\text {inorg }}: \mathrm{N}_{\text {org }}=65: 35 ; \mathrm{W} 14$ medium: total $\mathrm{N}=36.8$ mmol, $\mathrm{NO}^{-}: \mathrm{NH}^{+}=85.7: 14.3, \mathrm{~N}_{\text {inorg }}: \mathrm{N}_{\text {org }}=62.7: 37.3$. Larger differences were obtained in NLN medium (total $\mathrm{N}=31.38 \mathrm{mmol}, \mathrm{NO}^{-}: \mathrm{NH}^{+}=22.5: 77.5, \mathrm{~N}_{\text {inorg }}: \mathrm{N}_{\text {org }}=$
17.4:82.6) and MS medium (total $\mathrm{N}=73.7 \mathrm{mmol}$, $\left.\mathrm{NO}^{-}: \mathrm{NH}^{+}=65.7: 34.3, \mathrm{~N}_{\text {inorg }}: \mathrm{N}_{\text {org }}=81.4: 18.6\right)$.

When statistically analysed, significant differences were revealed among the tested media (Table 1). With regard to the effectiveness of the media, similar tendencies were found in both genotypes with B5 medium ranking first followed by W14, NLN and MS (Table 1). The best results were obtained on B5 and W14 media, which produced significantly higher number of microspore-derived structures than the NLN and MS media in microspore culture of the two genotypes.

Effects of growth regulators on the efficiency of microspore culture in sweet pepper

The different combinations of 2,4-D and kinetin were tested in two sweet pepper hybrid genotypes. Data of four parameters (microspore-derived ELS, calli, ratio of calli and ELS and regenerated plantlets) were collected to analyse the combined effect of the two growth regulators in the induction medium. Based on the statistical analysis of the collected data, it was concluded that growth regulators were not essential for the induction of androgenesis, although they had an overall influence on the effectiveness of microspore culture and the quality and quantity of microspore-derived structures.

Significant differences among the treatments were measured based on the number of ELSs, calli and ratio of calli and ELSs obtained in cultures. The calli and ELSs were subsequently transferred onto regeneration medium (Fig. 1). The number of ELSs and calli varied according to the added growth regulators applied (Fig. 1a, b). The number of calli increased along with the increasing levels of kinetin with the concentration of 2,4-D kept constant (Fig. 1b). The same tendency was obtained for the ratio of calli and ELS, too (Fig. 1c). The differences were more pronounced at higher concentrations of 2,4-D ( 0.2 and $0.5 \mathrm{mg} \mathrm{l}^{-1}$ ), but the tendency observed was similar at each 2,4-D level.

The size of calli increased with time on the regeneration medium, but they failed to produce any roots or shoots until the 3rd week of the regeneration period. The rooted structures were not able to produce shoots. Furthermore, 


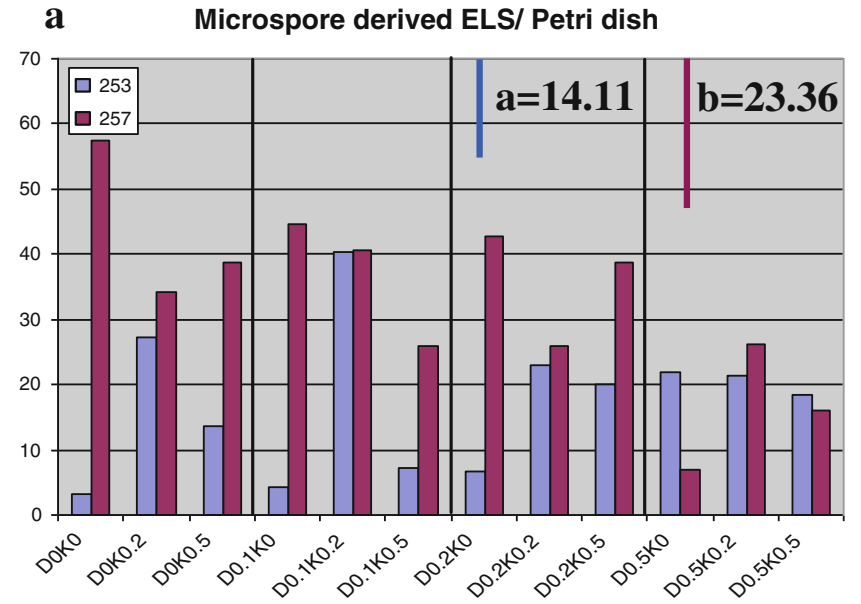

c

Ratio of calli and ELS

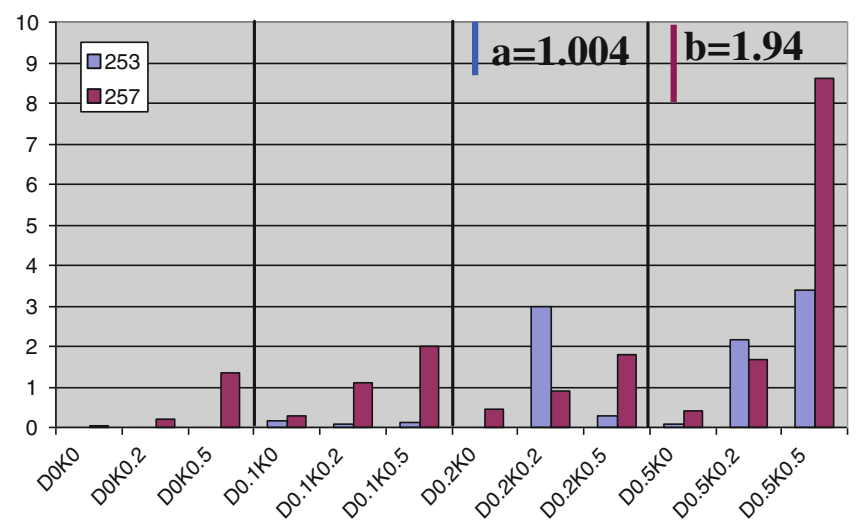

Fig. 1 Effects of growth regulators on a the number of microsporederived ELSs, $\mathbf{b}$ calli, $\mathbf{c}$ ratio of calli and ELS and $\mathbf{d}$ regenerated plantlets. Twelve different combination of 2,4-D (0, 0.1, 0.2 and $\left.0.5 \mathrm{mg}^{-1}\right)$ and kinetin $\left(0,0.2\right.$ and $\left.0.5 \mathrm{mg} \mathrm{l}^{-1}\right)$ were tested, and the

some structures regenerated shoots with leaf rosettes. Plantlet regeneration was observed only from the microspore-derived ELS. The statistical analysis of plantlet regeneration data revealed that the highest plant regeneration rate was achieved in the medium containing the combination of $0.1 \mathrm{mg} \mathrm{l}^{-1}$ 2,4-D and $0.2 \mathrm{mg} \mathrm{l}^{-1}$ kinetin (Fig. 1d).

The number of ELSs and regenerated plantlets were the two most important parameters studied with regard to androgenic response. The highest rates of ELS production were achieved in the growth regulator-free medium in the microspore culture of genotype 257 , while the medium containing the combination of $0.1 \mathrm{mg} \mathrm{l}^{-1} 2,4-\mathrm{D}$ and $0.2 \mathrm{mg}^{-1}$ kinetin produced the highest number of ELSs in the cultures of the genotype 253. Based on the number of regenerated plantlets, the medium containing the combination of $0.1 \mathrm{mg} \mathrm{l}^{-1}$ 2,4-D and $0.2 \mathrm{mg} \mathrm{l}^{-1}$ kinetin produced the highest number of plantlets in both genotypes. On the basis of the data and observations in the microspore culture

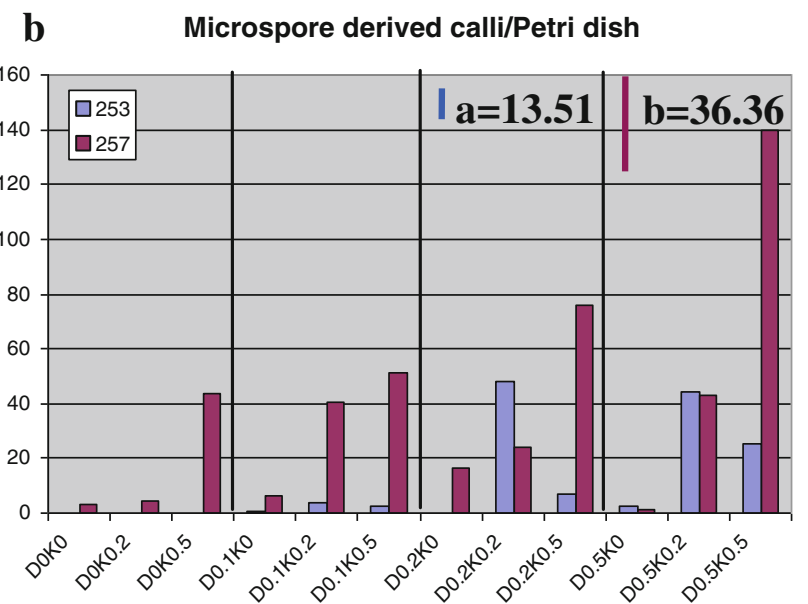

d Regenerated plantlets/Petri dish

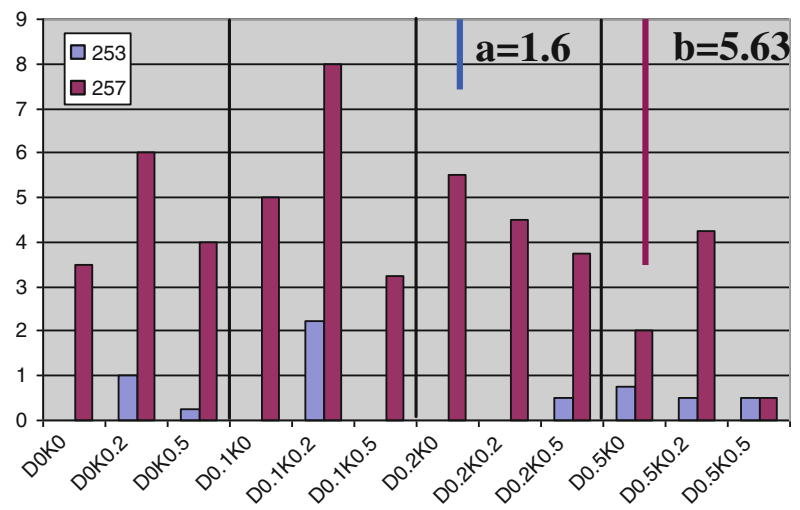

data were analysed by ANOVA. The letter in the right upper corner and the bars mark the value of LSDs calculated on the basis of data deriving from different treatments in microspore culture of genotype 253 (a) and 257 (b)

of genotypes 253 and $257, \mathrm{~B}_{5} \mathrm{D}_{0.1} \mathrm{~K}_{0.2}$ liquid media containing $0.1 \mathrm{mg} \mathrm{l}^{-1} 2,4-\mathrm{D}$ and $0.2 \mathrm{mg} \mathrm{l}^{-1}$ kinetin was chosen to test the response of sweet pepper genotypes.

Histological examination of microspore-derived structures

Different forms of morphogenesis were observed in the microspore cultures. In addition, the typical callus formation ELSs could be seen. At the early stages of culture development, these structures appeared similar to the naked eye and their distinctive developmental features could only be observed in detail under a light microscope.

Microspore originated ELSs seemed to circumvent some of the in planta developmental steps like the heart and cotyledonary stages. These microspore-derived ELSs developed from multicellular structures that differed from calli in many ways (Fig. 2). Isolated microspores first became round multicellular structures consisting of small 


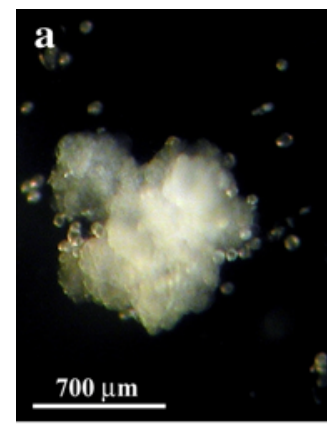

e

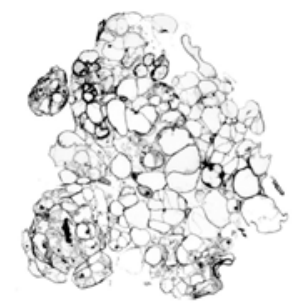

$350 \mu \mathrm{m}$

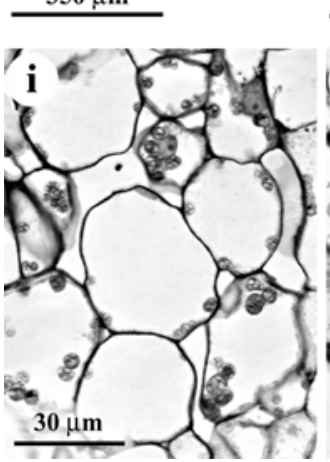

\section{.}

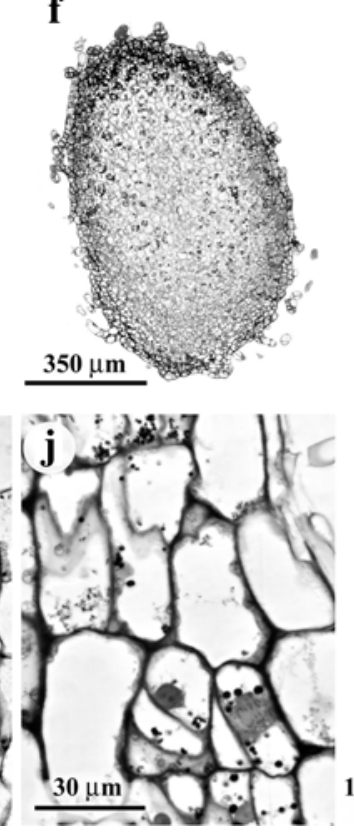

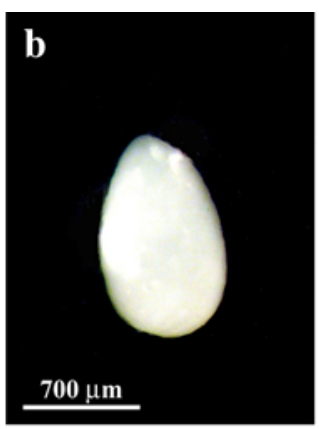

f

g
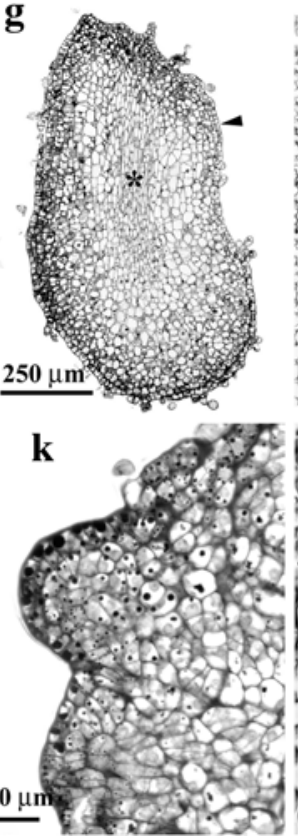
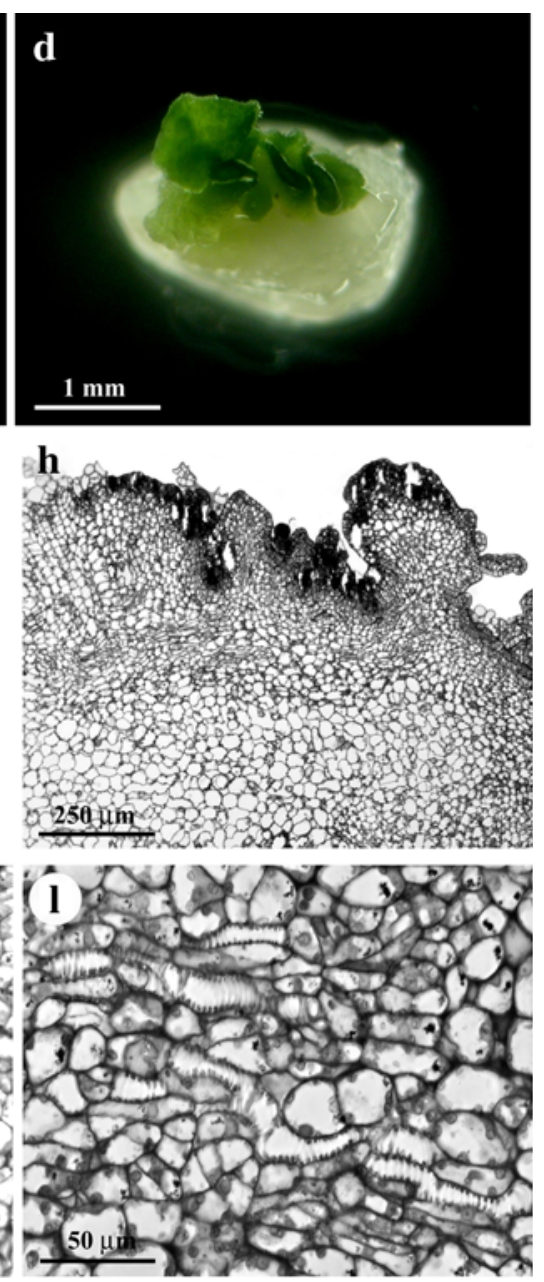

Fig. 2 Light micrographs of distinctive developmental stages of microspore originated structures. Bipolar stage ELS (b) were homogenous in section and the cytoplasm of the cells was densely filled with starch and lipid grains (f). At this stage, a small fraction of the cultured structures were observed to resemble regular calli consisting of enlarged, thin-walled and vacuolated cells (a, e). The ELSs assumed a heart-shaped formation (c). In cross-sectional view slightly elongated, smaller cells were observed at the central region, which formed a cylindrical bundle (asterisk in $\mathbf{g}$ ). The peripheral layer was made up of radially elongated cells with small diameter resembling a protodermal layer (arrowhead in $\mathbf{g}$ ). The underlying tissue comprised enlarged, vacuolated parenchymatic cells $(\mathbf{g}, \mathbf{i}, \mathbf{j})$. d The green, clubshaped apical portion of the ELS. Instead of shoot formation, the green pole became completely covered by small lobes. These bulges are surrounded with a protodermal layer consisting of small granulated cells (k). The lobe tissues show obvious signs of vascular element differentiation in their central region $(\mathbf{h}, \mathbf{l})$ uniform looking cells with thin walls. The cross-sectional view of the bipolar structures was homogenous and the cytoplasm of the cells was densely filled with starch and osmiofil lipid grains (Fig. 2f, i, j). There were other structures in the cultures that resembled regular calli consisting of enlarged, thin-walled, vacuolated cells (Fig. 2a, e).

When these multicellular structures developed further they assumed a shape that of a heart (Fig. 2c). In their cross-sectional view slightly elongated, smaller cells could be observed to form a cylindrical bundle. The peripheral layer was made up of thin, radially elongated and tightly connected cells resembling protodermal cells (Fig. 2g).
The underlying tissue consisted of enlarged, vacuolated parenchymatic cells (Fig. 2g, i, j).

The developmental transition of ELSs turning into plantlets was similar to that occurring during the germination of seeds in several respects. The ELSs developed their main radicle and a hypocotyl-like region at first followed by the apical portion of the ELSs becoming green. The well-developed ELSs were able to produce shoots while the other parts of ELSs showed abnormal shoot formation. The club-shaped green poles followed a peculiar developmental pattern (Fig. 2d). Instead of leaf and shoot formation the whole apical part of the ELS became undulated due to the meristems formed (Fig. 2k) and later 
developed small green lobes (Fig. 2d, h). These bulges were surrounded with a protodermal layer (Fig. 2k) and consisted of small thin-walled cells that accumulated starch (Fig. 2i) and lipid grains (Fig. 2j). The lobes showed obvious signs of cell differentiation in their central region. Xylem tissue elements with spiral/annular cell wall thickenings could be distinguished around the axis of the green lobes and in the underlying tissues (Fig. 2h, 1). Having their own vascular elements and typical shape- these structures were considered immature shoot primordia. The opposite pole of the ELSs developed a whitish unbranching main root completely covered with root hairs. This root consisted of a central vascular cylinder and a surrounding parenchymatic cortical layer (figure not shown).

Effect of genotype on ELS production and plant regeneration in sweet pepper genotypes

In this experiment- the androgenic response of 11 sweet pepper genotypes was tested in isolated microspore cultures. The pretreated isolated microspores were co-cultured with 7 wheat ovaries in $\mathrm{B}_{5} \mathrm{D}_{0.1} \mathrm{~K}_{0.2}$ liquid media. Microspore-derived structures were not visible to the naked eye until the 4th week of culturing. These structures were dominantly ELSs with more than 7 times more ELSs produced than calli. The average number of microsporederived ELSs was found to be 48.1 ELS/Petri dish (Table 2). Significant differences were observed among the pepper genotypes with regard to their ratio of microsporederived ELSs and calli (Table 2).

Table 2 Response of sweet pepper genotypes in isolated microspore culture

\begin{tabular}{lcrl}
\hline Genotypes & \multicolumn{2}{l}{$\begin{array}{l}\text { Microspore-derived structures } \\
\text { (number/Petri dish) }\end{array}$} & $\begin{array}{l}\text { Plant regeneration } \\
\text { (number/Petri dish) }\end{array}$ \\
\cline { 2 - 3 } & ELS & Calli & Plantlets \\
\hline 253 & $40.25 \mathrm{c}$ & $4.00 \mathrm{~b}$ & $2.25 \mathrm{bc}$ \\
257 & $40.50 \mathrm{c}$ & $40.50 \mathrm{a}$ & $8.00 \mathrm{a}$ \\
266 & $90.25 \mathrm{ab}$ & $0.50 \mathrm{~b}$ & $0.75 \mathrm{c}$ \\
267 & $24.75 \mathrm{c}$ & $0.00 \mathrm{~b}$ & $0.00 \mathrm{c}$ \\
269 & $72.75 \mathrm{~b}$ & $0.50 \mathrm{~b}$ & $3.00 \mathrm{~b}$ \\
278 & $69.50 \mathrm{~b}$ & $7.25 \mathrm{~b}$ & $0.75 \mathrm{c}$ \\
281 & $100.00 \mathrm{a}$ & $7.50 \mathrm{~b}$ & $1.25 \mathrm{bc}$ \\
287 & $24.25 \mathrm{c}$ & $3.25 \mathrm{~b}$ & $0.25 \mathrm{c}$ \\
291 & $25.75 \mathrm{c}$ & $0.50 \mathrm{~b}$ & $0.25 \mathrm{c}$ \\
292 & $21.25 \mathrm{c}$ & $0.75 \mathrm{~b}$ & $0.75 \mathrm{c}$ \\
303 & $20.00 \mathrm{c}$ & $8.25 \mathrm{~b}$ & $0.00 \mathrm{c}$ \\
LSD & 24.11 & 13.51 & 2.24 \\
Average & 48.1 & 6.64 & 1.54 \\
\hline
\end{tabular}

The same letters within a column indicate the data which are not significantly different at $P=0.05$
The calli were not able to produce shoots or roots until the 3 rd week of the regeneration period on regeneration medium. ELSs producing roots at first were not able to develop shoots. An average of 1.5 plantlets/Petri dish (from 0 to 8 plantlets/Petri dish depending on the genotypes) were regenerated from microspore-derived ELSs (Table 2) but those with leaf rosettes were subsequently unable to produce normal shoots and failed to acclimatize to greenhouse conditions.

The ploidy levels of well-rooted plantlets were determined by flow cytometry (Fig. 3). After flow cytometric analysis, the regenerated spontaneous diploid and haploid plantlets were planted in a greenhouse. A total of 28 acclimatized plants (4 from genotype 252, 4 from genotype 253, 1 from genotype 254 and 19 from genotype 257) were obtained in the experiments. After self-pollination, the spontaneous DH lines (based on flow cytometry) produced seeds. Genotypes 253 and 254 each produced one DH plant, whereas genotype 257 produced five. Based on these data, the spontaneous rediploidization rate was calculated to be $25 \%$ in isolated microspore culture of sweet pepper.

\section{Discussion}

Endogenous microbial contamination has long been regarded as a major problem in induction of androgenesis in pepper. In isolated microspore culture, the endogenous bacterial contamination of inocula resulted in significant losses in a number of isolated cultures, not only in our experiments but also in other laboratories (Supena et al 2006b). The problem prompted us to use Cefotaxime, a well-known and widely used antibiotic in tissue cultures to decrease the rate of contamination in the pretreatment procedure and to protect the microspores from undesirable infections while being cultured (Lantos et al, 2009). The combination of carefully monitored growing conditions of donor plants and the application of antibiotics in cultures made it possible to successfully induce androgenesis in isolated microspore cultures of sweet pepper genotypes (Lantos et al. 2009; Pauk et al. 2010).

Four different media-MS (Murashige and Skoog 1962), B5 (Gamborg et al. 1968), NLN (Lichter 1982) and W14 (Ouyang et al. 1989) widely used in cell and tissue cultures-were compared in isolated microspore cultures of sweet pepper (Capsicum annиum L.). Two of the media (NLN and W14) have been previously published as being used for DH plant production in microspore culture of pepper (Kim et al. 2008; Lantos et al. 2009). Significantly the best results were achieved by using B5 and W14 media in the microspore cultures of genotypes 254 and 257 . The media could be ranked in the following order with regard to their efficiency in microspore cultures for both genotypes: 

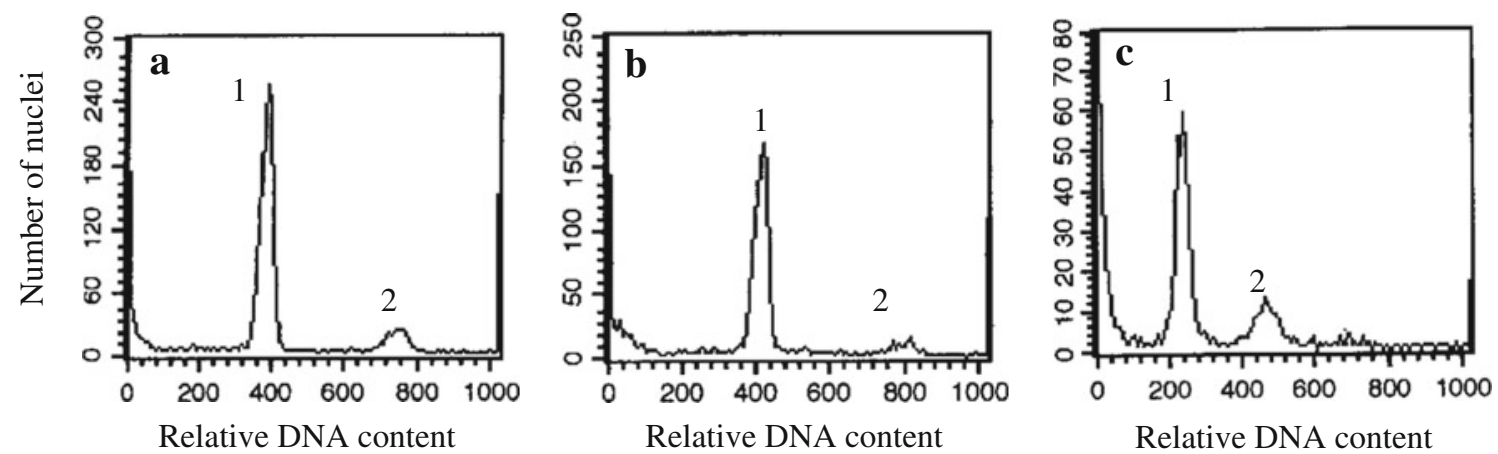

Fig. 3 Flow-cytometric ploidy level analysis of pepper plantlets. a Sample of a seed-derived control pepper plantlet. b A microspore culturederived spontaneous diploid plantlet. c A haploid regenerant from a microspore culture. Peaks a $12 \mathrm{C}, 24 \mathrm{C}$; b $12 \mathrm{C}, 24 \mathrm{C}$; and c $11 \mathrm{C}, 22 \mathrm{C}$

B5, W14, NLN and MS, demonstrating the superiority of B5 medium compared with the other three media. The source of $\mathrm{N}$ sources such as the total $\mathrm{N}$ content, $\mathrm{N}_{\text {org }}: \mathrm{N}_{\text {inorg }}$ ratio and $\mathrm{NO}^{-}: \mathrm{NH}^{+}$ratio in the induction media were determined and compared, because these factors were found to have a profound influence on the efficiency of microspore culture in barley (Mordhorst and Lörz 1993). The optimal parameters for barley microspore culture were found to be the following: $20-35 \mathrm{mmol}$ total nitrogen, a $\mathrm{NO}^{-}: \mathrm{NH}^{+}$ratio of $90: 10$ and a ratio of inorganic and organic nitrogen between 90:10 and 71:29 (Mordhorst and Lörz 1993). In our experiments in sweet pepper, these values were similar in B5 and W14 media, while larger differences were obtained among them in NLN and MS media. These experiments and calculations underlined the importance of media components and the ratios of components, especially those of the $\mathrm{N}$ sources and revealed the positive effects of the B5 medium.

In isolated microspore culture of Capsicum annuиm L., androgenesis was successfully induced with and without growth regulators. The combination of $0.5 \mathrm{mg}^{-1} 2,4-\mathrm{D}$ and $0.5 \mathrm{mg} \mathrm{l}^{-1}$ kinetin in the induction media was applied for androgenesis induction in six spice pepper varieties (Lantos et al. 2009). However, when exogenous growth regulators were omitted from the induction media, microspore-derived embryo formation and plant regeneration were still reported (Supena et al. 2006a; Kim et al. 2008). In the present study, the effects of 12 different growth regulator combinations, 2,4-D $\left(0,0.1,0.2\right.$ and $\left.0.5 \mathrm{mg}^{-1}\right)$ and kinetin $\left(0,0.2\right.$ and $\left.0.5 \mathrm{mg} \mathrm{l}^{-1}\right)$ in a $4 \times 3$ arrangement were tested in isolated microspore cultures with two sweet pepper genotypes. Four parameters (ELS, calli, ratio of calli and ELS, regenerated plantlets) were evaluated to test the effects of growth regulators on the rate of ELS production and plant regeneration in microspore culture. Androgenesis was reported to be induced without the presence of growth regulators in isolated microspore culture of pepper (Supena et al. 2006a; Kim et al. 2008). However, the different combinations of growth regulators influenced the quantity and quality of microspore-derived ELSs and calli and subsequent plant regeneration rates. The number of calli and ratio of calli and ELS increased with the increasing levels of exogenous growth regulators. Although the size of microspore-derived calli increased on the regeneration medium, they failed to produce roots or shoots. Microspore-derived ELSs produced mainly roots, while the shooting was suppressed in most treatments. The highest plant regeneration efficiency was achieved on the induction medium containing the combination of $0.1 \mathrm{mg} \mathrm{l}^{-1}$ 2,4-D and $0.2 \mathrm{mg} \mathrm{l}^{-1}$ kinetin. These results are in accordance with the published data for anther culture. Low concentration of 2,4-D $\left(0.01 \mathrm{mg} \mathrm{l}^{-1}\right)$ and kinetin $\left(0.01 \mathrm{mg} \mathrm{l}^{-1}\right)$ combinations have also been applied in a number of anther culture experiments (Dumas de Vaulx et al. 1981; Mitykó et al. 1995; Gyulai et al. 2000).

In order to optimise the culture conditions of isolated microspores to induce androgenesis, the embryogenic microspores have to be identified in the population (Lantos et al. 2009). It is possible for certain microspores to have naturally acquired potentials to form embryos. The phenomenon of forming two types of microspores in the anther is known as pollen dimorphism and can be observed in several plant species (Horner and Street 1978; HeberleBors 1982). It is not known which microspores in pepper microspore cultures are able to produce ELSs. In our isolated microspore cultures, certain microspores were partitioned by internal cell divisions and produced multicellular structures after being released from the pollen wall. The development of these cell groups was rapid and circumvented the steps typical of zygotic embryogenesis. Only a few of the globular structures were able to continue their development in the given culture conditions. In dicots, the globular stage is followed by the heart-shaped stage, when the acquisition of bilateral symmetry takes place. Epidermisation and the differentiation of the procambium and root meristems occur successively. Ordinarily, the shoot is formed much later during the cotyledon stage. In our microspore-derived embryo cultures, the root apex 
differentiated prematurely which was followed by an axial elongation of the ELS and normal root development. Since this stage cannot be observed during in vivo ontogenesis, it is likely to be induced by culture conditions. The metabolism of reserve materials resulted in intense accumulation of starch and lipids in the peripheral parenchymatic tissue. In our study, the apical pole development was shown to be delayed and irregular. This multi-lobed pole showed weak signs of differentiation. Due to their shape and ultrastructure, they can be considered to be immature shoot primordia. The absence of a mature and dominant shoot apex is the most crucial problem that can reduce plant regeneration efficiency. Light microscopy was applied to monitor the developmental processes.

Some research programmes were aimed at studying the effect of genotypes on the induction of androgenesis in Capsicum annum L. The effect of genotype on ELS production and plant regeneration has already been investigated in anther culture (Mitykó et al. 1995), shed microspore culture (Supena et al. 2006a) or isolated microspore culture (Lantos et al. 2009). In the present study, sweet pepper genotypes were used to improve the culture conditions of microspore cultures. The induction of androgenesis, cell divisions and formation of microsporederived structures were observed in the cultures of each genotype. The structures were dominantly ELS ranging from 20 to 100 ELS/Petri dish (an average of 48.1 ELS/ Petri dish). After the above-mentioned modification of the culture media, some sweet pepper genotypes $(266,269$, 278 and 281) produced a higher number of ELSs than previously published in isolated microspore culture of Milyang-yare genotype (54 embryos from a single bud) by Kim et al. (2008) or spice pepper genotypes (3.75-65.75 embryoids/Petri dish) reported by Lantos et al. (2009). The ELSs of most genotypes regenerated plantlets ranging from 0 to 8 plantlets/Petri dish depending on the genotypes with an average of 1.5 plantlet/Petri dish. The number of ELSs and plant regeneration were influenced by the genetic background of the donor material. These results are similar to the published data of isolated microspore culture in spice pepper (Lantos et al. 2009), in anther culture (Mitykó et al. 1995; Dolcet-Sanjuan et al. 1997) and shed microspore culture (Supena et al. 2006a).

The rate of plant regeneration from microspore-derived ELSs varied between 0 to 8 plantlets/Petri dish. Plant regeneration is known to be a critical step in pepper haploid induction methods (Seguí-Simarro et al. 2011), which proved to be even more problematic in liquid media (Supena et al. 2006a). Furthermore, defective shoots were obtained not only in haploid induction but also in somatic embryogenesis (Steinitz et al. 2003) and organogenesis (Steinitz et al. 1999; Ochoa-Alejo and Ramírez-Malagón 2001). A total of 28 regenerated plantlets $(4,4,1$ and 19 from genotypes 252, 253, 254 and 257, respectively) were able to acclimatise to the greenhouse conditions, 7 of which produced fruits with seeds. The ploidy level of the regenerated in vitro plantlets was determined by flow cytometry. The spontaneous rediploidization rate was $25 \%$ in our experiment, which is a relatively low value in haploid induction systems. In shed microspore culture of pepper, this rate ranged from 14 to $51 \%$ depending on the genotypes (Supena et al. 2006a), while in anther culture, it varied from 32.6 to $65 \%$ (Mitykó et al. 1995; Gyulai et al. 2000; Dolcet-Sanjuan et al. 1997).

In conclusion, androgenesis was successfully induced in isolated microspore cultures of sweet pepper. The superiority of the B5 medium were demonstrated in terms of the number of microspore-derived structures produced. Moreover, the combination of $0.1 \mathrm{mg}^{-1} 2,4-\mathrm{D}$ and $0.2 \mathrm{mg} \mathrm{l}^{-1}$ kinetin was shown to be the most effective for the induction of androgenesis in sweet pepper microspore cultures. The limiting factor was found to be the abnormal shoot formation of the ELSs. Spontaneous rediploidization rate of microspore-derived plants was found to be $25 \%$. Further experiments will be aimed at improving the quality of microspore-derived embryos and increasing the rate of plant regeneration.

Acknowledgments This work was supported by the HungarianRomanian Cross-border Co-operation Programme, 2007-2013 (HURO/0801/143, acronym: RedpepperTRD) and National Office for Research and Technology-Hungarian Scientific Research Fund (OTKA CK80719 and OTKA CK80766). The authors thank Szilvia Palaticki, Zsuzsanna Kun, Ferenc Markó for their conscientious work.

\section{References}

Csilléry G (2006) Pepper taxonomy and the botanical description of the species. Acta Agron Hung 54:151-166

Dolcet-Sanjuan R, Claveria E, Huerta A (1997) Androgenesis in Capsicum annuиm L. Effect of carbohydrate and carbon dioxide enrichment. J Am Soc Hortic Sci 122:468-475

Doležel J, Binorova P, Lucretti S (1989) Analysis of nuclear-DNA content in plant-cells by flow-cytometry. Biol Plant 31(2):113-120

Dumas de Vaulx R, Chambonet D, Pochard E (1981) Culture in vitro d'anthères du piment (Capsicum annuum L.): amélior des taux d'obtention de plantes chezdifférents génotypes par des traitments ŕ+ 35 C. Agronomie 1:859-864

Gamborg OL, Miller RA, Ojima K (1968) Nutrient requirements of suspension cultures of soybean root cells. Exp Cell Res 50:151-158

Gémes Juhász A, Lantos CS, Pauk J (2010) New perspective: microspore culture as new tool in paprika breeding. In: Book of advances in genetics and breeding of capsicum and eggplant XIVth EUCARPIA meeting on genetics and breeding of capsicum and eggplant, Valencia, Spain, pp 377-381

Gémesné Juhász A, Lantos C, Vági P, Kristóf Z, Pauk J (2009) In vitro anther and isolated microspore culture as tools in sweet and spice pepper breeding. Acta Hortic 829:423-431

Gémes Juhász A, Vencel G, Sági Zs, Gajdos L, Kristóf Z, Vági P, Zatykó L (2006) Production of doubled haploid breeding lines in 
case of paprika, eggplant, cucumber, zucchini and onion. Acta Hortic 725:845-854

George L, Narayanaswamy S (1973) Haploid Capsicum through experimental androgenesis. Protoplasma 78:467-470

Gyulai G, Gémesné Juhász A, Sági Z, Venczel G, Pintér P, Kristóf Z, Törjék O, Heszky L, Bottka S, Kiss J, Zatykó L (2000) Doubled haploid development ad PCR analysis of F-1 hybrid derived DHR-2 paprika (Capsicum annuum L.) lines. J Plant Physiol 156: $168-174$

Harms CT, Potrikus I (1978) Fractionation of plant protoplast types iso-osmotic density gradient centrifugation. Theor Appl Genet 53:57-63

Heberle-Bors E (1982) In vitro pollen embryogenesis in Nicotiana tabacum L. and its relation to pollen sterility, sex balance and floral induction of the pollen donor plants. Planta 156:396-401

Horner M, Street HE (1978) Pollen dimorphism-origin and significance in pollen plant formation by anther culture. Ann Bot 42:763-771

Irikova T, Grozeva S, Rodeva V (2011) Anther culture in pepper (Capsicum annuum L.) in vitro. Acta Physiol Plant 33:1559-1570

Jedrzejczyk I, Nowaczyk P (2009) In vivo polyembryony induction in species of Capsicum. Acta Biol Cracov Bot 51:55-60

Kim M, Jang IC, Kim JA, Park EJ, Yoon M, Lee Y (2008) Embryogenenesis and plant regeneration of hot pepper (Capsicum anпиит L.) through isolated microspore culture. Plant Cell Rep 27:425-434

Kim M, Kim J, Yoon M, Choi DI, Lee KM (2004) Origin of multicellular pollen and pollen embryos in cultured anthers of pepper (Capsicum annuum L.). Plant Cell Tissue Org Cult 77:63-72

Kristiansen K, Andersen SB (1993) Effect of donor plant-temperature, photoperiod, and age on anther culture response of Capsicum annuum L. Euphytica 67:105-109

Kuo JS, Wang ZZ, Chien NF, Ku SJ, Kung ML, Hsu HC (1973) Investigation on the anther culture in vitro of Nicotiana tabacum L. and Capsicum annuum L. Acta Bot Sin 15:43-47

Lantos C, Gémes Juhász A, Somogyi Gy, Ötvös K, Vági P, Mihály R, Kristóf Z, Somogyi N, Pauk J (2009) Improvement of isolated microspore culture of pepper (Capsicum annuит L.) via co-culture with ovary tissues of pepper or wheat. Plant Cell Tissue Org Cult 97(3):285-293

Lichter R (1982) Induction of haploid plants from isolated pollen of Brassica napus. Z Pflanzenphysiol 105:427-434

Mitykó J, Andrásfalvy A, Csilléri G, Fáry M (1995) Anther-culture response in different genotypes and F1 hybrids of pepper (Capsicum annuum L.). Plant Breed 114:78-80

Mitykó J, Gémes Juhász A (2006) Improvement in the haploid technique routinely used for breeding sweet and spice pepper in Hungary. Acta Agron Hung 54:203-219

Mordhorst AP, Lörz H (1993) Embryogenesis and development of isolated barley (Hordeum vulgare L.) microspores are influenced by the amount of nitrogen sources in culture media. J Plant Physiol 142:485-492
Murashige T, Skoog F (1962) A revised medium for rapid growth and bioassays with tobacco tissue cultures. Physiol Plant 15:473-497

Ochoa-Alejo N, Ramírez-Malagón R (2001) In vitro chilli pepper biotechnology. In Vitro Cell Dev Plant 37:701-729

Ouyang JW, Jia SE, Zhang C, Chen X, Fen G (1989) A new synthetic medium (W14) for wheat anther culture. In: Annual report, Institute of Genetics, Academia Sinica, Beijing, pp 91-92

Parra-Vega V, Palacios-Calvo N, Corral-Martínez P, Seguí-Simarro JM (2010) Establishment of isolated microspore cultures in pepper of the California and Lamuyo types. In: Prohens J, Rodríguez-Burruezo A (eds) Advances in genetics and breeding of Capsicum and eggplant. UPV Press, Valencia, pp 411-415

Pauk J, Lantos C, Somogyi G, Vági P, Ábrahám Táborosi Z, Gémes Juhász A, Mihály R, Kristóf Z, Somogyi N, Tímár Z (2010) Tradition. Quality and biotechnology in Hungarian spice pepper (Capsicum annuum L.) breeding. Acta Agron Hung 58:259-266

Seguí-Simarro JM, Corral-Martínez P, Parra-Vega V, GonzálezGarcia B (2011) Androgenesis in recalcitrant solanaceous crops. Plant Cell Rep 30:765-778

Sibi M, Dumas de Vaulx R, Chambonnet D (1979) Obtention de plantes haploïdes par androgenèse in vitro chez le piment (Capsicum annuиm L.). Ann Amélior Plantes 29:583-606

Simonne AH, Simonne EH, Eitenmiller RR, Mills HA, Green NR (1997) Ascorbic acid and provitamin A contents in unusually colored bell peppers (Capsicum annuum L.). Food Compo Anal 10:299-311

Steinitz B, Wolf D, Matzevitch-Josef T, Zelcer A (1999) Regeneration in vitro and genetic transformation of pepper (Capsicum spp.). The current state of art. Capsicum Eggplant Newslett 18:9-15

Steinitz B, Kusek M, Tabib Y, Paran I, Zelcer A (2003) Pepper (Capsicum annum L.) regenerants obtained by direct somatic embryogenesis fail to develop a shoot. In Vitro Cell Dev Plant 39:296-303

Supena EDJ, Suharsono S, Jacobsen E, Custers JBM (2006a) Successful development of a shed-microspore culture protocol for doubled haploid production in Indonesian hot pepper (Capsicum annuum L.). Plant Cell Rep 25:1-10

Supena EDJ, Muswita W, Suharsono S, Custers JBM (2006b) Evaluation of crucial factors for implementing shed-microspore culture of Indonesian hot pepper (Capsicum annиum L.) cultivars. Sci Hortic 107:226-232

Thomas WTB, Forster BP, Gertsson B (2003) Doubled haploids in breeding. In: Maluszynski M, Kasha KJ, Forster BP, Szarejko I (eds) Doubled haploid production in crop plants. A manual. Kluwer, Dordrecht, pp 95-102

Touraev A, Ilham A, Vicente O, HeberleBors E (1996) Stress-induced microspore embryogenesis in tobacco: an optimized system for molecular studies. Plant Cell Rep 15:561-565

Wang YY, Sun CS, Wang CC, Chien NF (1973) The induction of the pollen plantlets of triticale and Capsicum annuum from anther culture. Sci Sin 16:147-151 